Table 1

Transformed Means and SDs for Four Reveral Conditions for Two Experiments

\begin{tabular}{|c|c|c|c|c|}
\hline \multirow[b]{2}{*}{ Condition } & \multicolumn{2}{|c|}{ Experiment 1} & \multicolumn{2}{|c|}{ Expeximent 2} \\
\hline & Mean & SD & Mean & SD \\
\hline $\begin{array}{l}\text { No Change (Control) } \\
\text { Size Change Alone } \\
\text { Color Change Alone } \\
\text { Color and Size Change }\end{array}$ & $\begin{array}{l}9.59 \\
9.49 \\
7.34 \\
7.44\end{array}$ & $\begin{array}{l}2.03 \\
2.86 \\
2.41 \\
1.46\end{array}$ & $\begin{array}{l}9.35 \\
7.40 \\
6.67 \\
8.36\end{array}$ & $\begin{array}{r}2.62 \\
1.08 \\
.61 \\
2.05\end{array}$ \\
\hline
\end{tabular}

problems, and procedure were identical to those used in the previous experiment with the following exceptions: (1) the stimuli were initially one-half the size of those employed in Experiment 1, i.e., $2.5 \mathrm{sq}$ in.; and (2) instead of reducing the size of the stimuli, as was the case for Group 3 in Experiment 1, the stimuli were doubled in size during reversal.

\section{Results}

An analysis of variance of the training phase scores indicated no differences $(F<1.0)$ among the four treatment groups. The percentage of errors during reversal was again subjected to a $\sqrt{\mathrm{X}}+\sqrt{\mathrm{X}+1}$ transformation. An analysis of variance of these transformed scores indicated a significant difference $(F=84.75, d f=3 / 40, p<.001)$ over the four reversal conditions. Each of the experimental groups was then compared with the control group, using Dunnett's procedure. The color change $(p<.01)$ and size change $(p<.05)$ groups were both reliably different from the control group. However, contrary to prediction and the results of Experiment 1, the combined color-change and size-increase group failed to differ from the no-change group.

\section{DISCUSSION}

The main hypothesis in the present experiments was that the more similar the initial training condition and the reversal condition, the slower the reversal speed. This has partially been confirmed. The results indicate that color change alone, during test problems, produced the most rapid reversal learning. Size change alone also facilitated reversal in one experiment, but in another its only influence appeared to be when associated with a color change. However, further examination of the mean values suggests that the facilitatory effect was largely due to the color cue. The discrepant result produced by manipulating the size variable may be a function of the direction in which the change occurred. When size change alone was effective, the direction of change was from small to large. When size appeared to have minimal influence, the direction of change was from large to small. Consequently, it is possible that when size is decreased, its saliency is reduced in a compound stimulus situation.

It is not clear why the effectiveness of the combined color and size cue change was restricted to the size decrease condition. One possible size cue may have allowed the more distinctive color cue to overshadow the weaker size cue, thereby permitting the color cue to control RS performance. Conversely, in the size-increase condition in Experiment 2, where the combined color-size effect was not significant, a novel color cue in combination with a relatively salient size cue may have provided some competition between the cues or served as distractors for S's attention, thus eliminating any significant facilitatory effect. These findings appear to indicate that the combined effects of both color and size change during test problems did not produce maximum reversal speed explanation is that reduction in the not the $S$ attempted to utilize it.
In a recent investigation of mnemonic structuring (Haney \& Norristown State Hospital, Norristown, Pa. 19401.
+Now at the Department of Psychology, as expected. Although speculative, it is plausible that the very young child's attention or cue sampling is restricted to one highly salient background cue during reversal trials.

The results of the two studies suggest that variation in the dominant cues associated with discriminanda utilized in training and test problems can influence reversal speed, possibly by increasing the probability of cue sampling in the test problem and reducing the number of repetitive errors. Such evidence is relevant to studies which attempt to compare RS with nonreversal shift (NRS) learning. Since the stimuli associated with both training and test problems are typically more similar for one type of shift (RS) than another (NRS), comparisons between shifts may be partially explained on the basis of variations in stimulus conditions.

REFERENCES

FRITZ, B., \& BLANK, $M$. Role of the irrelevant cue in rapid reversal learning in nursery school children. Jourmal of Comparative \& Physiological Psychology, $1968,65,375-378$.

VINEY, W., BOYER, W., VINEY, W. Effect of variations in a reinforcement complex upon reversel shift performance of kindercarten children. Psychonomic Science, 1969, 16, 206-207.

\title{
The effects of disorganizing cues on the utilization of a mnemonic structure*
}

\author{
JACK N. HANEY $†$, JAMES L. BRUNING, and JERRY NOSIN \\ Ohio University, Athens, Ohio $\mathbf{4 5 7 0 1}$
}

To test the hypothesis that disorganizing cues would impair total recall and disrupt the utilization of a mnemonic structure, four groups of Ss were given a list in a free-recall task which was a combination of mnemonic structure (serial or random order) and cuing paradigm (organizing or disorganizing cues). Results revealed that (1) the mnemonic structure enhanced total recall, (2) disorganizing cues tended to disrupt the utilization of the mnemonic structure, and (3) a significant relationship was seen between the nature of the cue and whether or

Bruning, 1970), it was found that "cue saliency," the extent to which Ss were aware of the relationship between task-associated cues and stimuli to be recalled, was directly related to (1) organizational efficiency of output and $(2)$ total recall. These results were interpreted to suggest that $\mathrm{Ss}$ tended to employ a wide range of their own 
idiosyncratic structuring of task-associated cues when the nature of the experimental mnemonic structure available to them was not made explicit.

The present investigation presented Ss with the mnemonic paradigm previously employed (Haney \& Bruning, 1970), while at the same time providing cuing procedures that were hypothesized to be either organizing or disorganizing. Organizing cues were defined as those which were (1) relevant to the to-be-recalled stimuli, and (2) facilitating to the perception of the mnemonic available to them. Disorganizing cues were cefined as those which were (1) task irrelevant and (2) interfering with the utilization of the mnemonic in that they suggested a counterstrategy and increased memory load. Based on previous research dealing with cue utilization (Zaffy \& Bruning, 1966 ; Bruning et al, 1968), it was hypothesized that disorganizing cues would impair total recall and disturb utilization of the mnemonic as evidenced in the disorganization of recalled material.

\section{SUBJECTS}

The 30 males and 42 females participating in the study were either freshmen or sophomores enrolled in introductory psychology courses at Ohio University.

\section{EXPERIMENTAL DESIGN}

AND PROCEDURE

The 15 trigrams employed were those used in a previous study (Haney \& Bruning, 1970). Four lists were composed by the combinations of two orders (alphabetical or random) and two types of cues (organizing or disorganizing). Eighteen Ss were assigned randomly to each of the four groups, corresponding to the four lists. In the experimental group receiving alphabetized presentation of the trigrams and organizing cues (A-O), the trigrams were alphabetized from $\mathrm{A}$ through $\mathrm{O}$, and a cue letter identical to the first letter of the trigram was printed $1 \mathrm{in}$. to the left of each trigram. In the alphabeticaldisorganizing condition (A-D), the trigrams were again presented in alphabetical order, but the cue letters did not correspond to the first letter of the trigram. In the random-organizing condition (R-O), the trigrams were presented in random order, but the cue letter matched the trigram, while in the random-disorganizing condition (R-D), the trigrams were randomized and the cue letters were not matched to the first letter of the trigrams.
All Ss were read standard instructions and were told that their task was to learn the trigrams. They were further told that the single letters to the left of each trigram were cues to be used to aid in learning, but that there was no necessity to recall the single letters. After all questions were answered, the stimuli were presented at a 1 -sec rate with a 2 -min intertrial interval in which the Ss were to write down as many of the syllables as they could recall. Five trials were administered, after which the $\mathbf{E}$ administered a postexperimental questionnaire to determine the $\mathrm{Ss}^{\prime}$ specific techniques used in memorizing the list.

\section{RESULTS AND DISCUSSION Free Recall}

The number of correctly recalled trigrams for each of the four experimental groups indicated that the $A-O$, and $R-O$ groups displayed the highest level of recall ( $\overline{\mathrm{X}}=40.83$ and 40.45 ), while the A-D and R-D groups showed the lowest $(\overline{\mathrm{X}}=34.89$ and 29.33). These data were analyzed as a three-factor analysis of variance, having between-S factors of order and cue with repeated measures on trials. This analysis showed that organizing cues significantly enhanced the overall level of free recall $(F=8.35$, $\mathrm{d} \dot{f}=1 / 68$ ), but that other between-Ss comparisons were nonsignificant. The within-Ss portion of the analysis revealed significant effects of trials ( $F=215.07, \quad \mathrm{df}=4 / 272)$, Trials by Cue $(F=2.97, \mathrm{df}=4 / 272)$, and Trials by Order $(\mathrm{F}=3.31, \mathrm{df}=4 / 272)$. These interactions suggest that both alphabetization of the trigrams and cue saliency resulted in more rapid learning.

\section{Mnemonic Utilization}

Assessment of the extent to which each $S$ actually utilized the serial mnemonic was done by counting the number of adjacent pairs of syllables given in the response list. A summary of the number of adjacent pairs revealed that: those $S$ s receiving the organizing cue with the alphabetized list (A.O group) demonstrated more serialized output $(\overline{\mathrm{X}}=\mathbf{2 3 . 1 1})$ as compared to the other groups $(\mathrm{A} \cdot \mathrm{D}=13.61, \mathrm{R} \cdot \mathrm{O}=4.72$, $\mathrm{R}-\mathrm{D}=2.61$ ).

The analysis of variance revealed that the main effects for order $(\mathrm{F}=34.59, \mathrm{~d} f=1 / 68)$ and cue $(F=5.40, d f=1 / 68)$ were significant.

The within-Ss analysis of adjacent pairs showed significant effects for trials $(F=46.25, \mathrm{df}=4 / 272)$, Trials by Order $(F=20.19$, df $=4 / 272)$, and trials cue $(F=3.39$, df $=4 / 272)$.
It is of interest to note that the main effect for order failed to reach significance when overall recall of trigrams was measured. Yet, order was a highly significant variable when adjacent pairs were measured. The fact that highly significant differences were evidenced in output organization, but with no significant difference in total recall, suggests that the disorganizing cues interrupted use of the serial mnemonic, permitting other learning strategies that were just as efficient as serialization.

Postexperimental Inquiry

The Ss, responses to postexperimental questionnaires revealed that, for the organizing cue groups, $56 \%$ said they attempted to use the cues, while $11 \%$ of the Ss who were presented the disorganizing cues stated they attempted to use them.

These data were analyzed with a 2 by 2 chi square $\left[x^{2}(1)=15.90\right.$, $\mathrm{p}<.001$, phi $=.47]$. From this, it may be concluded that there was a significant relationship between the nature of the cue and whether or not the Ss attempted to utilize it.

It should be noted, however, that while $89 \%$ of those individuals in the disorganizing cue groups reported they consciously attempted to ignore the cues, the highly significant and consistent decrements in total recall and disruption of organization in output suggest these Ss were not really capable of achieving this. These findings are in disagreement with those of Morin, Forrin, \& Archer (1961), who concluded that their Ss"... . were remarkably efficient in filtering out irrelevant stimulus information [p. 95]."

\section{REFERENCES}

BRUNING;, J. L., CAPAGE, J. E., KOZUH, P. F, YOUNG, P. F., YOUNG, W. E. Socially induced drive and range of cue utilizátion. Joumal of Personality \& Social Psychology, 1968, 9, 242-244.

HANEY, J. N: \& BRUNING, J. L. Cue saliency: A relevant variable in the utilization. Psychonomic Science, 1970 , 20, 85-86.

MORIN, R. E., FORRIN, B., \& ARCHER, W. Information processing behavior: The role of irrelevant stimulus information. Journal of Experimental Psychology. $1961,61,89-96$.

ZAFFY, D. J., \& BRUNING. J. L. Drive and the range of cue utilization. Journal of Experimental Psychology, 1966, 71, 382-384. 